\title{
Experimental Study on Re-refining of Used Lubricating Oil
}

\author{
Prof. S B Bobde ${ }^{1}$, Miss Anamika B Admane ${ }^{2}$, Mr. Nikhil N Kalekar ${ }^{3}$, Mr. Nikhil N Jadhav ${ }^{4}$ \\ Department of Chemical Engineering ${ }^{1,2,3,4}$, Finolex Academy of Management and Technology Ratnagiri. ${ }^{1,2,3,4}$ \\ Email: shrikrishna.bobde@famt.ac.in ${ }^{1}$, anamikaadmane01@gmail.com ${ }^{2}$
}

\begin{abstract}
During normal use, impurities such as dirt, metal scrapings, water or chemicals can get mixed in with the oil or be generated in it due to thermal degradation or oxidation. Used engine oil itself contains a number of additives and is contaminated by impurities and a residue resulting from the combustion process. This paper review a method by which the spent oil is adequately recycled for reuse, the cost of recycling is relatively low compared to production of lubricating oil from crude oil as the numbers of purification stages are reduced. In used lube oil contains poisonous and carcinogenic like lead and PAH (poly-aromatic hydrocarbons) etc. Also the oils used in transformers contain PCB's (polychlorinated biphenyls), which are highly carcinogenic as well. From various sources, used lubricating oils are generated and are disposed improperly. The burning of used oil in kilns and incinerators produces lots of ash and carcinogens causing environmental pollution. The most important used oil recycling technology is the re-refining. With these processes high quality base oil can be produced. By proper recovery and refinement of it, a lot of valuable product can be obtained. The objective of re-refining is to remove the degraded additives and contaminants and to restore the properties of the oil identical to the standards provided by SAE (Society of Automobile Engineers), the re-refined base oil characteristics using solvent extraction have a slight difference, compared to the virgin oil.
\end{abstract}

Keywords: Base oil, contaminants, Viscosity, Re-refining, Spent Oil.

\section{INTODUCTION}

A lubricant (engine oil) can be defined as an oil product that separates the metal parts of an engine, reduce friction and keep it clean. Lubricant deals with the application of lubricating oil to machine ${ }^{[1]}$. Lubricants were at one time exclusively animal or vegetable oils of fats, but modern requirement in both nature and volume have petroleum as the main source of supply ${ }^{[3]}$. The lubricating oil can be produced by modern method of refining from most crude and they range from thin easily flowing spindle oils to tank cylinder oils [2]. The lubrication system of engine is intended to avoid the increase of wear, overheating and seizure of rubbing surfaces to reduce the expenditure of indicated power on overcoming mechanical losses in the engine and also to remove wear products of a machine ${ }^{[3]}$. There are four major types of lubricant namely-liquid, solid gaseous and plastics Lubricant, example of lubricants include oil, grease, air and graphite ${ }^{[4]}$. Liquid and plastics lubricant are the most commonly used lubricant in industries because they are inexpensive, easily applied and good coolants while Gaseous and Solid lubricant are recommended only in some special application ${ }^{[5]}$.In view of the problem encountered, lubricating oil is designed to impact varieties of properties and to protect engine in so many ways. Lubricating oil is highly specialized product carefully developed to perform many essential functions among which are the following ${ }^{[7]}$.Permit easy starting of engine, reduced friction between moving parts, protecting machine against rust and corrosion, Lubricating of engine parts etc ${ }^{[3]}$.

\section{LUBRICATING ADDITIVES}

The purification and manufacturing processes impact good qualities to lubricating oils. But still they cannot be used directly ${ }^{[2]}$. They will be prone to contamination and decomposition in the exacting working conditions ${ }^{[6]}$. Hence certain chemical compounds and other agents which are termed as additives are added to the oil. Most modern lubricant additives can be classified as follows: 1. those designed to protect the lubricant in service by maintaining deterioration.2.Those that protect the lubricant from harmful fuel combustion products.3. Those which improve existing physical properties or impart new characteristics. Use of chemical additives in lubricants is very wide. Generally speaking, the additives must have the following properties: Solubility in base petroleum oil. b) Insolubility in and lack of reaction with aqueous solution. c) Should not impart dark color to the oil d) Low volatility e) Additives must be stable in blending, storage and use. f) Additives should not impart unfavorable odor.4-6 maintenance engineering and management ${ }^{[9]}$.

Additives are substances formulated for improvement of the anti-friction, chemical and physical properties of base oils (mineral, synthetic, vegetable or animal), which results in enhancing the lubricant performance and extending the equipment life ${ }^{[6]}$.Combination of different additives and their quantities are determined by the lubricant type (Engine oils, Gear oils, Hydraulic oils, cutting fluids, Way lubricants, compressor oils etc.) and the specific operating conditions (temperature, loads, machine parts materials, environment). Amount of additives may reach $30 \%$. Some of the additives are as follows:

- Friction modifiers

- Anti-wear additives

- Extreme pressure (EP) additives

- Rust and corrosion inhibitors

- Anti-oxidants

- Detergents

- Dispersants

- Pour point depressants 
International Journal of Research in Advent Technology, Vol.7, No.4, April 2019

E-ISSN: 2321-9637

Available online at www.ijrat.org

- Viscosity index improver

\section{COMPOSITION OF ENGINE OIL}

The most important consideration in engine oil is the reduction of friction and control of wears where viscosity is the primary factor performance which was obtained by blending base stock or base oil with various compositions of various additives ${ }^{[4]}$. Hence achieving the right viscosity relies on selecting the right base stocks and blending recycled oil with performance additives to enhance functional performance ${ }^{[8]}$. The chemical composition of the lubricating oil is usually preserved to a large amount because of the high stability of the heavy compounds contain in the base oil ${ }^{[10]}$. Used lubricating oils which difficult to handle anthropogenic pollutant due to its toxicity and become undesirable for use. The recycling of waste oil may be an appropriate and cheap alternative to and burn incineration. Typically, lubricants contain $98 \%$ base oil $-2 \%$ additives ${ }^{[6]}$.

Additive

Fig 1.1: Composition of lubricant oil.

\section{LUBRICANT CHARACTERISTICS}

Following are the characteristics of lubricating oil: 4.1 Specific Gravity:

It is the ratio of the weight of a given volume of substance at 60 -degree $\mathrm{F}$ to that of water. This is normally expressed in kilograms per cubic meter or grams per cubic centimeter at $15^{\circ} \mathrm{C}$. As the density of the fuel depends upon the density of the individual components ${ }^{[8]}$.Apart from being an indicator of the 'heaviness' of a fuel, when measured by a hydrometer, the specific gravity can be used to calculate the quantity of fuel by weight in a tank of given dimensions.

\subsection{Viscosity:}

It is a measure of the oil resistance to flow. The more the viscosity of the oil more will be its resistance to flow, e.g. compare water and molasses ${ }^{[6]}$. Water is less viscous and hence flows freely whereas molasses, which has a high viscosity, flows sluggishly. An ideal oil film on a bearing depends on selecting oil with the right viscosity to maintain separation of two metal surfaces. The speed of the journal and viscosity are closely allied in maintaining a good oil film in the bearing ${ }^{[6]}$. The slower the journal speed, the higher viscosity or thicker oil we must use. As journal speeds are increased, a thinner of lower viscosity oil is needed ${ }^{[4]}$. Bearing loads must also be considered because the oil must have sufficient viscosity to maintain a good oil film to support the load. Technically speaking, it is defined as the force required moving a plane surface of one square centimeter area over another plane surface at the rate of one centimeter per second, when the two surfaces are separated by a layer of liquid one centimeter in thickness. The unit of this force is poise and is called absolute viscosity. Kinematic viscosity is the ratio of absolute viscosity to the specific gravity of the oil at the 45 maintenance engineering and management temperature at which the viscosity is measured. Its unit is stokes ${ }^{[4]}$. For practical purposes, viscosity of petroleum oils is expressed in time in seconds taken by a given quantity of oil to flow through a standard capillary tube. It is expressed as Say bolt universal seconds at 100-degree F. or 210-degree F.

\subsection{Viscosity Index}

It is an expression of effect of change of temperature on the viscosity of oils. This change can be evaluated numerically and the result is expressed as V.I. Once a viscosity index had been defined in 1929 there was a desire to improve the viscosity index of base-oils (Dean and Davis, 1940). Modification by the addition of polymers allowed year round operation of lubricants in a wide range of climates ${ }^{[9]}$. The viscosity index of automotive engine oil has received considerable attention. Starting requires low viscosity at low temperature but normal operation requires maintaining an adequate fluid film near $149^{\circ} \mathrm{C}$. Mineral oils have been able to meet these wide temperature-range viscosity requirements through the use of high-molecular weight polymeric additives known as VI improvers ${ }^{[8]}$. At low temperatures, these polymers are sparingly soluble in oil and exist as closely coiled chains with little influence on the viscosity of the oil ${ }^{[6]}$. As the temperature increases, the polymer becomes more soluble and expands into loose, random coils ${ }^{[9]}$.These expanded polymers restrict movement of the oil molecules and serve to reduce the rate at which oil thins out with increasing temperature. Various polymethacrylates, olefin co-polymers, hydrogenated polyisoprene and styrenebutadiene co-polymers have been used as VI improvers. The amount of thickening they provide depends on the size of the polymer molecule ${ }^{[7]}$.

\subsection{Flash Point \& Fire Point}

It is the lowest temperature at which the oil lubrication gives off enough vapors that ignite for a moment, when a tiny flame is bought near it is called ad FLASH POINT \& the lowest temperature at which the vapors of the oil burn continuously for at least five seconds, when a tiny flame is brought near it is called FIRE POINT. The flash \&fire points do not have any bearing with the lubrication property of the oil, but these are important when oil is exposed to high temperature service. ${ }^{[7]}$.A good lubricant should have flash point at least above the temperature at which is to be used. The flash \& fire point is, usually, determined by using pesky marten's apparatus.

\subsection{Pour Point \& Cloud Point}

When oil is cooled slowly, the temperature at which it becomes cloudy or hazy in appearance is called its called cloud point; while the temperature at which the oil ceases to flow or pour is called as pour point. Cloud point \& pour 


\section{International Journal of Research in Advent Technology, Vol.7, No.4, April 2019 E-ISSN: 2321-9637 \\ Available online at www.ijrat.org}

point indicates the suitability of lubricants in cloud conditions. ${ }^{[2]}$.Lubricant used in a machine working at low temperature should possess low pour point; otherwise solidifications of lubricant will causes jamming of the machine. It has been found that presence of waxes in the lubricating oil raise the POUR POINT.

\subsection{Acid Number}

The number of milligrams of $\mathrm{KOH}$ required neutralizing the free acids in $1 \mathrm{~g}$ of the oil. Generally free acids are not present in the lubricants, unless refined in faulty manner. Lubricating oil should possess acid value less than .1. Value greater than 0.1 indicates that oil has been oxidized ${ }^{[10]}$. This will, consequently lead to corrosion besides gum and sludge formation. it is also called as Neutralization number

\section{LITERATURE REVIEW}

Jesusa Rincon et.al. [9] have described that by the proper selection of components and compositions, a composite solvent to recover base oil from used lubricant oil has been formulated. The composite solvent has two single components: methyl ethyl ketone (MEK) and 2propanol. The best extraction results were obtained when the single solvents selected were mixed at a 2-propanol $/ \mathrm{MEK}$ ratio of $3 \mathrm{~g} / \mathrm{g}$. However, this solvent was still unable to completely remove metals and oxidation products. To solve this problem, very small quantities of $\mathrm{KOH}$ [from 1 to $7 \mathrm{~g} /$ ( $\mathrm{kg}$ of solvent)] were added to the composite solvent and its effect on both the extraction yields and the quality of the oil recovered was determined. A $\mathrm{KOH}$ concentration of $2 \mathrm{~g} /$ ( $\mathrm{kg}$ of solvent) were found to be the most appropriate. The vacuum distilled oil pre-treated with this solvent (2-propanol/MEK at a weight ratio of $3 \mathrm{~g} / \mathrm{g}$ with 2 ( $\mathrm{g}$ of $\mathrm{KOH}) /(\mathrm{kg}$ of solvent)) was almost similar to virgin oil and, therefore, suitable for the formulation of new lubricants

Bob Boughton et.al. [10] Have investigated that management of used oil has local, regional and global impacts. Because of the globally distributed nature of fuel markets, used oil as fuel has localized and regional impacts in many areas. In this paper, the human health and environmental tradeoffs of the management options are quantified and characterized. The goal of this study was to assess and compare the environmental impacts and benefits of each management method in a product end-of-life scenario using a lifecycle Assessment (LCA) approach.

\section{MATERIAL \& METHODS}

\section{Process: 1 - Dehydration}

The oil is heated to $130^{\circ} \mathrm{C}$ in a closed vessel to boil off emulsified water and some of the fuel diluents. The point at which oil contains the maximum amount of dissolved water is termed the saturation point. Higher the temperature, higher is the saturation point and hence more water held in solution, in the dissolved phase. Similarly, older the oil, higher is the level of water that can be dissolved. Water is a generator of other contaminants in the oil such as waxes, suspensions, carbon and oxide insoluble and even microorganisms, so it is removed by dehydration.

Water can also affect the additive package through water washing and hydrolysis .leading to acids and additive depletion. Water encourages rust and corrosion and will cause increased wear as result of aeration changes in viscosity resulting in film strength failure, vaporous cavitations. Finally, water is a generator of other contaminates in the oil such as waxes, suspension carbon and oxides insoluble and even micro-organisms.

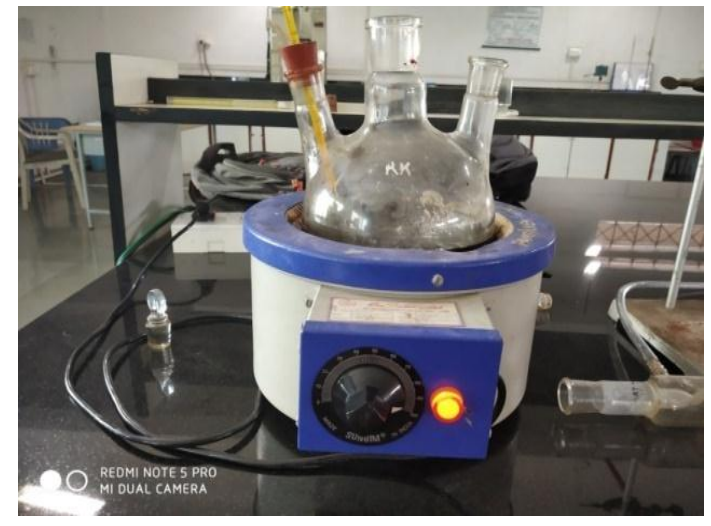

Fig 1: Dehydration Unit

\section{Process: 2 - Vacuum Distillation}

Petroleum oil is mixture of hundreds of different hydrocarbon compounds generally having from 3 to 60 carbon atoms molecule, although there may be small amounts of hydrocarbon outside that range. The re-refining of crude begins with distilling the incoming crude oil in a so called atmospheric distillation column operating at pressure slightly above atmospheric pressure. In distilling oil, it is important not to subject the crude oil to temperature above 370 to $380{ }^{0} \mathrm{C}$ because the high molecular weight components in crude oil will undergo thermal cracking and form petroleum coke at temperature above that. Formation of the coke would resulting in plugging in the tubes in the furnaces that heat feed stream to the crude oil distillation column. Plugging would also occur in the piping from the furnaces to the distillation column as well as in the column itself The constraints imposed by limiting the column inlet crude oil to a temperature of less than 370380 0C yields a residual oil from the bottom of the atmospheric distillation column consisting entirely of hydrocarbon that boil above 370 to 380 0C. To further distillate the residual oil from the atmospheric distillation column, the distillation performed at absolute pressure as low as 10 to $40 \mathrm{mmHg}$.so as to limit the operating temperature to less than 370 to 380 0C. The vacuum distillation column internals must provide good vapour-liquid contacting while, at the same time, maintaining a very low pressure increases from the top of the column top to the bottom. Therefore, the vacuum column uses distillation trays only where withdrawing products from the side of the column (referred to as side draws). Most of the column uses packing material for the vapour-liquid contacting because such packing has a lower 
pressure drop than distillation trays. This packing material can be either structured sheet metal or randomly dumped packing such as Rasching rings. The dehydrated oil is then fed continuously into a vacuum distillation plant for fractionation in exactly the same fashion as crude petroleum. The fractions obtained are as follows:

1. Light fuel and diesel: It can produce enough diesels from the used oil feedstock to run all the burners and boilers, giving total self-sufficiency in fuel.

2. Lubricating oil: The bulk of the feedstock will distillate off in the plant to produce a lubricating oil fraction.

3. Residue: The non-distillable part of the feedstock. This contains all the carbon, wear metals, degraded additives and most of the lead and oxidation products. This residue is successfully used as bitumen extender for roading [5].

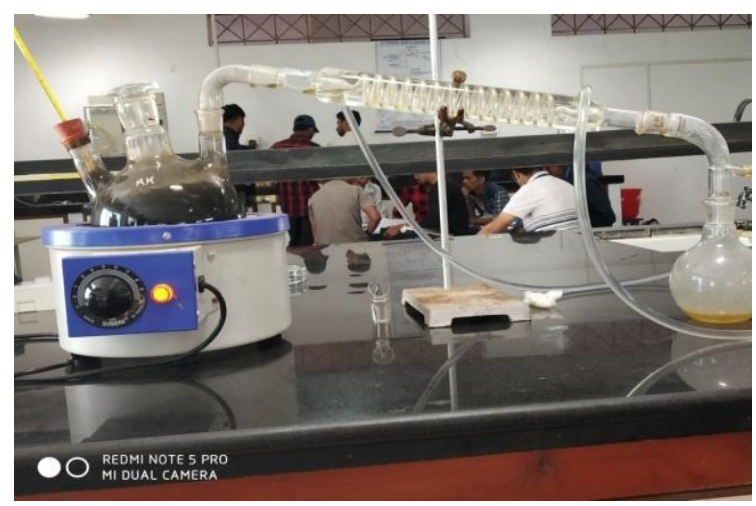

Fig 2: Vacuum Distillation Unit

Step 3: Lube oil distillation and condensation

The lubricating oil fractions are then passed through an extraction tower in the presence of methyl ethyl ketone (NMK).The NMK is an aromatic selective solvent. Is able to extract all unwanted aromatic contaminates present in the paraffinic lube oil fractions, subsequent to fractional distillation. This is important as polycyclic aromatics are very carcinogenic. This re-refining process is commonly used in virgin oil refineries.

Liquid -liquid extraction also known as solvent extraction is method to separate components based on their relative solubility in two different soluble liquids .usually water and organic solvent. It is an extraction of substances from one liquid into another phase. Liquid -liquid extraction is a basic technique in chemical laboratories where it is performed using a separating funnel. This type of process is commonly performed a chemical reaction as part of the work -up

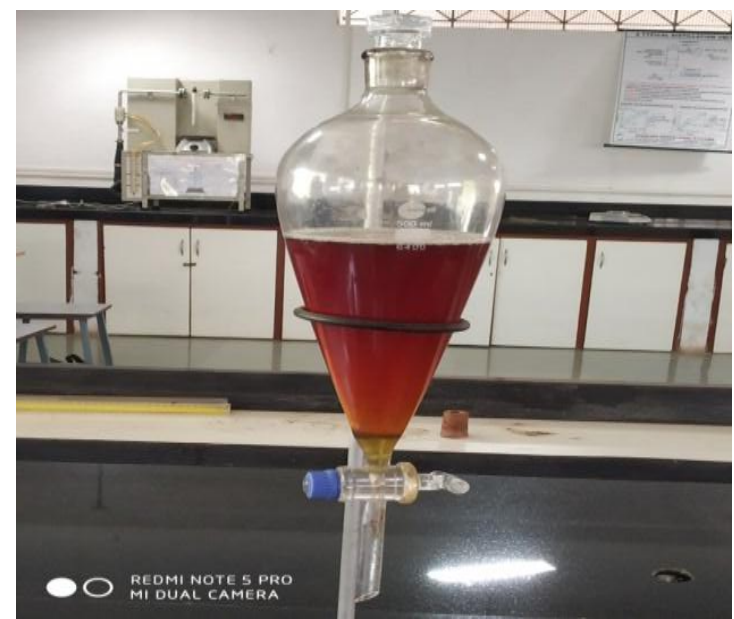

Fig 3: Solvent Extraction

\section{RESULTS AND DISCUSSION}

Table1.0: Used and Re-Refining Lubricating oil testing samples analysis [10W30]

\begin{tabular}{|l|l|l|l|}
\hline Sr.No & Properties & Used Oil & $\begin{array}{l}\text { Re-refined } \\
\text { Oil }\end{array}$ \\
\hline 1 & Density & $0.91 \mathrm{gm} / \mathrm{cc}$ & $0.87 \mathrm{gm} / \mathrm{cc}$ \\
\hline 2 & Flash Point & $401.15 \mathrm{~K}$ & $458.15 \mathrm{~K}$ \\
\hline 3 & Fire Point & $407.15 \mathrm{~K}$ & $465.15 \mathrm{~K}$ \\
\hline 4 & Water Content & 2 & 0.01 \\
\hline 5 & TAN & 2.9 & 0.922 \\
\hline 6 & Residue & 22 & - \\
\hline 7 & Pour Point & - & - \\
\hline 8 & $\begin{array}{l}\text { Viscosity at } 40 \\
\text { cSt }\end{array}$ & 193.17 & 120.12 \\
\hline 9 & $\begin{array}{l}\text { Viscosity at } \\
100 \text { cSt }\end{array}$ & 22.13 & 12.23 \\
\hline
\end{tabular}

Because of the combustion process in the engine the density of the oil. Viscosity of the oil is decreased flash and fire point is increased and calorific value is increased because of the mixture of fuels in the used engine oil.

Table1.1: Used and Re-Refining Lubricating oil Testing samples analysis [20W40]

\begin{tabular}{|l|l|l|l|l|l|}
\hline $\begin{array}{l}\text { Sr. } \\
\text { No }\end{array}$ & Properties & $\begin{array}{l}\text { Dehy } \\
\text { drati } \\
\text { on }\end{array}$ & $\begin{array}{l}\text { Vacuu } \\
\mathbf{m} \\
\text { Distilla } \\
\text { tion }\end{array}$ & $\begin{array}{l}\text { Solven } \\
\mathbf{t} \\
\text { Extrac } \\
\text { tion }\end{array}$ & $\begin{array}{l}\text { Addin } \\
\text { g } \\
\text { Additi } \\
\text { ves }\end{array}$ \\
\hline 1 & $\begin{array}{l}\text { Volume of } \\
\text { Sample }\end{array}$ & 1000 & 716 & 712 & 300 \\
\hline 2 & Pressure & ATM & $\begin{array}{l}6 \\
\mathrm{mmHg}\end{array}$ & ATM & ATM \\
\hline 3 & Temperature & 130 & $\begin{array}{l}320- \\
350\end{array}$ & 25 & 80 \\
\hline 4 & $\begin{array}{l}\text { Settling } \\
\text { Hours }\end{array}$ & & & 48 & - \\
\hline 5 & $\begin{array}{l}\text { Solvent } \\
\text { Recovery }\end{array}$ & & & & $70 \%$ \\
\hline 6 & Process time & 20 & 206 & 2880 & 17 \\
\hline
\end{tabular}




\begin{tabular}{|l|l|l|l|l|l|}
\hline & (min) & & & & \\
\hline 7 & $\begin{array}{l}\text { Viscosity } \\
\text { cSt }\end{array}$ & 13.5 & 8.2 & 8.2 & 8.5 \\
\hline 8 & $\begin{array}{l}\text { Flash Point } \\
\text { K }\end{array}$ & 156 & 201 & 215 & 234 \\
\hline 9 & Fire Point K & 163 & 207 & 223 & 248 \\
\hline 10 & $\begin{array}{l}\text { TAN (mg } \\
\text { KOH/g of } \\
\text { lube) }\end{array}$ & $\begin{array}{l}\text { (2.48 } \\
11\end{array}$ & $\begin{array}{l}\text { Water } \\
\text { content (ml) }\end{array}$ & 20 & \multicolumn{4}{|l}{} \\
\hline 12 & Residue (ml) & - & 260 & 4 & $<0.01$ \\
\hline
\end{tabular}

\section{IMPORTANCE OF RE-REFINING}

1) Reduce dependence on base oil imports saving foreign exchange. 2) Prevent ground water contamination and pollution. Reduce sewage treatment costs. 3) Preserve natural resources such as coal and crude oil. 4) Eliminate improper burning of waste oil as fuel, which generates toxic fumes $\&$ air pollution ${ }^{[5]}$.

\section{SAFETY IN OIL INDUSTRY}

In an industry dealing with highly flammable hydrocarbons, safety must always be a prime consideration of management. This is especially the case in refineries and loading terminals which are located in urban communities. There can be few more horrifying sights than a boiling liquid expanding volume explosion (BLEVE) which suddenly devastates all around its source. As in all other industry, safety must be considered a line management responsibility and safety performance should be regarded as part of the employee's overall job performance ${ }^{[5]}$.In the provision of safe operating facilities, personal protective equipment and regular plant maintenance the oil industry normally adopts a higher standard than the legislation required by the particular country in which it is operating. Variations between companies tend to be in areas such as setting realistic practical safety goals, motivation of employees, regular training, monitoring of and acceptance of responsibility for safety performance by management ${ }^{[8]}$. These topics are well covered in two HSE Occasional Paper Series, Managing Safety and Monitoring Safety Injury and accident statistics provided by individual oil companies frequently show much lower than national average rates for serious injuries and fatalities. Cynics might remark that this is due to the dangerous jobs being given to contractors -exploration drilling, diving and tank cleaning being but three examples ${ }^{[5]}$. This does raise the important point that the overall responsibility of a manager for safety does extend to all contractor operations within his work site. Injury and accident statistics must be regarded as one index only of total safety performance and then as an index of failure. They should be interpreted with caution since they take no account of inherent risk. Comparison between different countries is fraught with error ${ }^{[6]}$.

\section{CONCLUSION}

The study proved that vacuum distillation is a process that can effectively remove contaminants from used lubricating oil ${ }^{[6]}$. The recovered oil has a comparable quality with the fresh oil indicating the possibility of reusing it ${ }^{[1]}$. Used engine oil properties were determined with standard chemical and physical tests. The characterization implied that the oil was contaminated with light fuel from extraneous and/or products of oil degradation; oxidation and polymerization products; water from extraneous source; soot and carbon originating from incomplete fuel combustion and oil components break down; organic acids and soaps of heavy metals; and metals from engine parts wearing. Valuable light fuel oil was also recuperated from the vacuum distillation $\operatorname{step}^{[5]}$. This product had a similar characteristic that was comparable with gas oil ${ }^{[9]}$. It could be used to supply the energy requirement in the larger scale recycling plant. Regarding cost effectiveness of the process, the difference in the imported oil price and the cost incurred for reclaiming used oil increased the appeal of the recycling process to be implemented and gave an insight of its potential and opportunities for scale up. Re-refining of waste lubricants could result in both environmental and economic benefits [10].

\section{REFERENCES}

[1] Durrani H.A, Panhwar M.I, Kazi, R.A, "Re-refining of waste lubricating oil by solvent extraction", Mehran University Research Journal of Eng. \& Tech., 237-246. 30 (2), 2011.

[2] Ademola, B and Luxembourg M, A new Approach to caustic treatment of waste treatment and utilization. Journals of Engineering Technology, 3(2): 43-47. 2001.M.I. Abdul_Mutalib, N.O. Elbashir, M. Sahrif, R. Adnan, Practical use of the solubility parameters in determining effective solvent extraction parameters for recycling used lubricating oil, proceedings of RSCE98, Manila, Philippines, pp. 110-117., 1998.

[3] Hamad, E. Al-zubaidy, M.E. Fayed, Used lubricating oil recycling usinghydrocarbon solvent, J-Unviron. Manage. 153-159.74 (2005).

[4] Francois, A. "Waste Engine Oils Refining and Energy Recovery", 1st ed.; Elsevier Science and Technology Books: Amsterdam, The Netherlands, 2006.

[5] Ogbeide S.O, "An Investigation to The Recycling of Spent Engine Oil", Journal of engineering science and technology review.

[6] J. D. Udonne, "A comparative study of recycling of used lubricating oils" Journal of petroleum and Gas Engineering, vol2

[7] Rahman, M. M., Siddique, T. A., Samdani, S. and Kabir, K. B., "Effect of operating variables on regeneration of base-oil from waste oil by conventional acid-clay method", Chemical Engineering Research Bulletin 12, 24-27. (2008)

[8] Jain \& Jain Engineering Chemistry, $16^{\text {th }}$ edition, Jain. Jain (2016). 